\title{
Analysis of a Voltage Instability Incident in the Greek Power System
}

\author{
C. D. Vournas \\ Natıonal Technical University \\ P O.Box 26137 \\ .thens 10443 . Greece \\ i-mall: 、 ournas(â.)power.ece.ntua.gr
}

\author{
J. Kabouris \\ Public Power Corporation \\ Dyrrachioy \& Kifissoy St. \\ Athens 104 43. Greece \\ e-mail: kabourısiommal.dei.gr
}

\author{
T. Van Cutsem \\ University of Liège, Institut .Montefiore \\ Sart-Tilman B28. \\ B-4000, Liège, Belgıum \\ e-mall: vct@montefiore.ulg.ac.be
}

\begin{abstract}
The paper reports on a 1996 incident in the Greek power system that had all the characteristics of voltage instability and the subsequent analyses and countermeasures. Voltage stability analysis is performed by both NTUA and ULg software tools that give identical simulation results. After the upgrades performed by PPC a considerable increase in the maximum power that can be fed to the $\Lambda$ thens area is achieved. Finally, secure operation limits of the upgraded system are calculated.

Keywords oltage stability, long-term simulation, quası-steadystate approxımation, secure operation limits. maximum power transfer.
\end{abstract}

\section{INTRODUCTION}

Voltage stability is a growing concern for many power systems around the globe. Following this general trend. during the summer of 1996 the Interconnected Greek Power System owned and operated by the Public Power Corporation (PPC) experienced a low-voltage incident that highlighted the need for detailed voltage stability studies. A first study of the incident was conducted at the National Technical University of Athens (NTUA) [1] and it demonstrated that the load demand had exceeded the maximum power that could be transferred to Athens and the southern part of the system. The simulation results were validated using tools developed at the University of Liège (ULg) [2].

As a result of this and other similar studies conducted by PPC several measures were taken to increase the maximum power transfer to the Athens region. Also, a second project was launched [3] as a result of which PPC obtained a voltage stability analysis program developed by NTUA [4].

In the following section we give a short description of the Greek power system and the 1996 incident. In Section III we present the voltage stability tools developed at NTUA and ULg, which were applied for the analysis of the Greek system. Section IV gives an analysis of the 1996 incident and Section $V$ the countermeasures taken by PPC to reinforce the system. Finally, in Section VI voltage security analysis of the upgraded system is performed using the concept of secure operation limits [5].

\section{II.DESCRIPTION OF THE EVENT}

\section{A. The Greek Power System}

Public Power Corporation (PPC) is a national vertically !ntegrated electric utility serving the generation, transmission and distribution needs of Greece.
The interconnected grid of PPC covers the Greek mainland and the electrically connected main islands of the Ionian Sea as well as few adjacent islands in the Aegean Sea: autonomous power grids cover the electric needs of the other islands. Fig. I illustrates a single line diagram of the Greek power system. The main production center of PPC is in the north of Greece in the vicinity of the lignite rich area of Ptolemaida. Thermal power plants in this area generate about $70 \%$ of the total electricity in the Greek mainland. Significant hydro production exists in the north and the northwest of the country. There is also important lignite production in the sciuthern peninsula of Peloponnese; natural gas and oil-fired generation exist also near Athens. Due to the natural geography, all international interconnections, with the neighboring systems of Albania (with $150 \mathrm{kV}$ and $400 \mathrm{kV}$ lines), Bulgaria (one $400 \mathrm{kV}$ line) and former Yugoslavia (150 $\mathrm{kV}$ and $400 \mathrm{kV}$ lines), are also in the North.

The salient feature of the Greek power system is that the main production center is located at the northwest of the country while the main consumption is in the metropolitan area of Athens. The above system characteristics lead to significant electric power transmission in the north-south direction, from the main generation center to the major load sink. Several critical operating conditions are associated with this geographical unbalance of generation and load.

Transmission needs are served by $400 \mathrm{kV}$ and $150 \mathrm{kV}$ transmission lines. The $400 \mathrm{kV}$ transmission network plays the primary role in the energy transport to Athens. There is no 400 $\mathrm{k} V$ transmission south of Athens. The $150 \mathrm{kV}$ network covers the secondary transmission needs as well as radial distribution needs in the Athens area. The distribution system of PPC is operating radially at $22 \mathrm{kV}, 15 \mathrm{kV}$ and very limited $6.6 \mathrm{kV}$ voltage levels.

The load of the system peaks during the summer when severe voltage stability problems may occur in case of reduced generation availability in the Southern part of the system. During this period, the loads are strongly inductive due to the big percentage of motors (air-conditioning in residential loads and irrigation needs in the central part of the country).

\section{B. The July 1996 event}

On the $8^{\text {th }}$ of July, 1996 four generating units feeding the $150 \mathrm{kV}$ network in the southern part of the system with a total capacity of $580 \mathrm{MW}$ were out of operation.

The problem started at 09:45 and lasted until 13:00. During this period the voltages of the $150 \mathrm{kV}$ network in the Athens region fell to approximately $120 \mathrm{kV}(0.8 \mathrm{pu})$, while the voltages of the $400 \mathrm{kV}$ network were near $0.83 \mathrm{pu}$; the voltage levels at the Northern part of the system remained at normal lisvels throughout. 


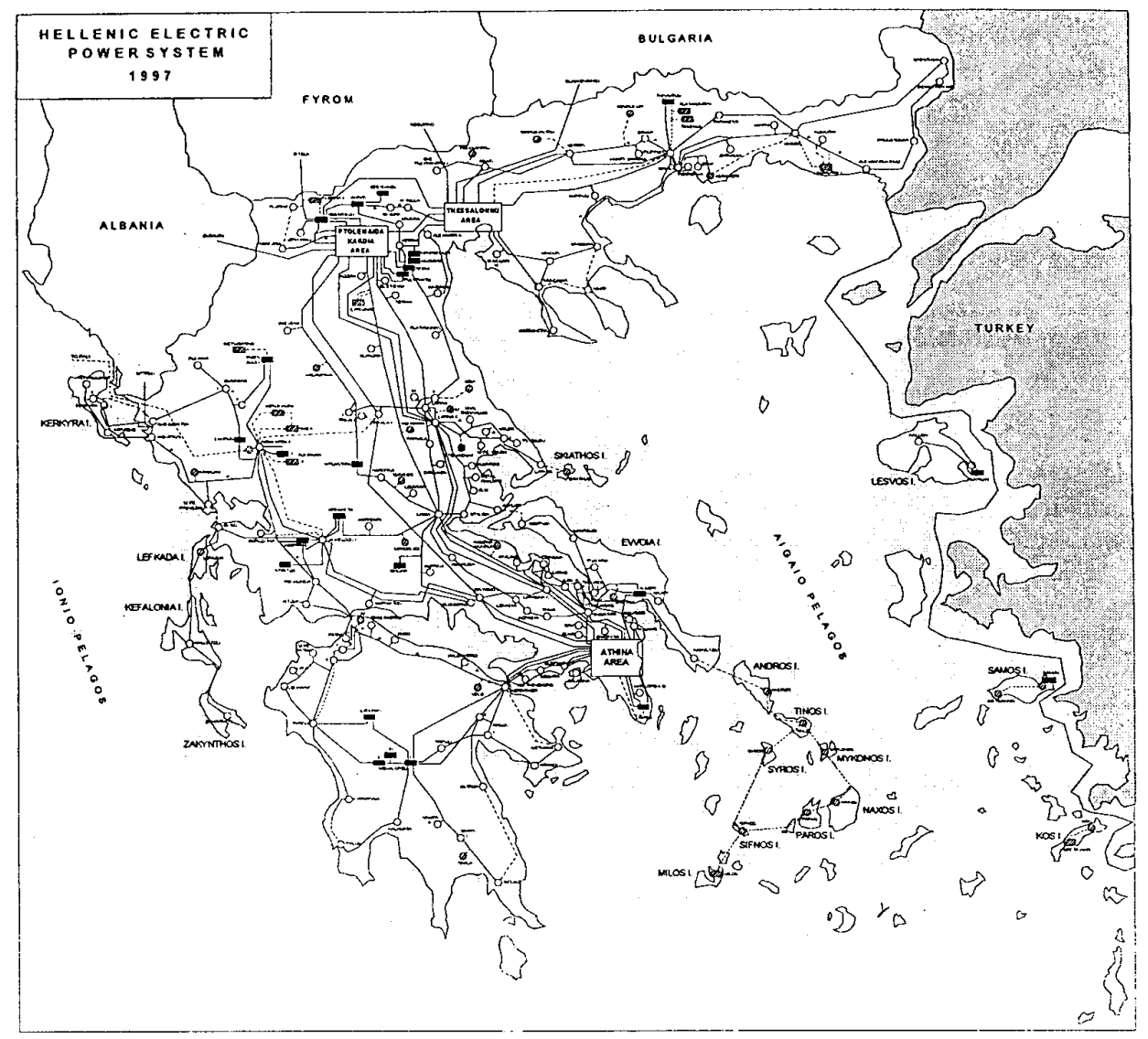

Fig. 1.The Power System of Greece

The voltage drop rates observed during the incident were $0.75 \mathrm{kV} / 5 \mathrm{~min}$ from $9: 00$ to $9: 45$ and then increased to 1.8 $\mathrm{kV} / 5 \mathrm{~min}$ from $9: 45$ to $10: 30$. The voltage drop was quite large for relatively small load increase: for $20 \mathrm{MW}$ load increase the voltage drop was $2 \%$ ( $3 \mathrm{kV}$ in the $150 \mathrm{kV}$ system). This observation was an indication of voltage instability.

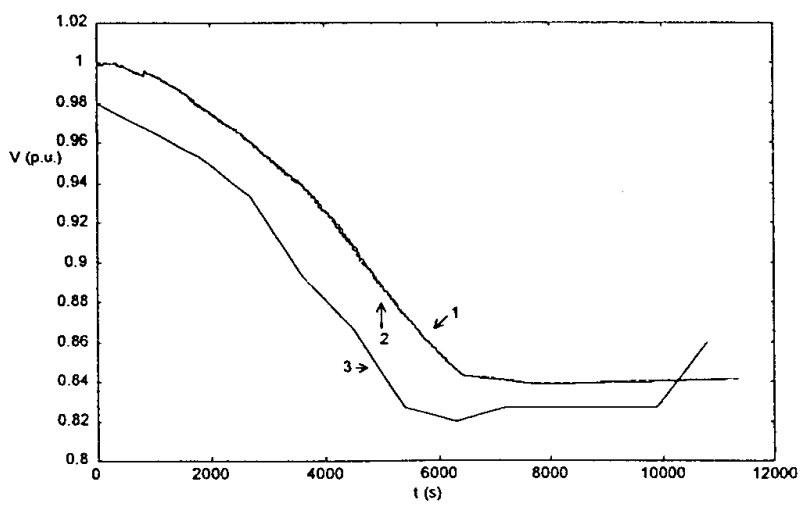

1: WPSTAB, 2: ASTRE, 3: measurement

Fig. 2. Voltage of a $150 \mathrm{kV}$ bus in the Athens region
Fig 2 presents the voltage profile at a $150 \mathrm{kV}$ substation in the Athens region. Line 3 shows the measured voltages during the incident as retrieved from the EMS files. Lines 1 and 2 in the same figure are the simulation results described in the next section.

The voltage drop stopped at 12:30 when load of about 100 MW was disconnected (in Athens and Thessaloniki areas) due to the triggering of an overload protection scheme of the interconnection line with former Yugoslavia. Even after the load shedding the voltages remained at low levels until the peak hour passed.

The phenomenon described above did not lead to total or partial blackout, but considerable concern was raised as to the possible consequences of other similar events.

\section{COMPUTATIONAL TOOLS}

\section{A. QSS simulation}

Two computer programs have been used to study the 1996 incident and assess the voltage security of the upgraded system. They both rely upon the Quasi Steady State (QSS) approach $[6,7]$ based on the time-scale decomposition of power system dynamics and a simplified representation of the short-term dynamics, when focusing on long-term phenomena. Thus, during long-term simulation: 
- The differential equations, describing the dynamic behavior of a power system (e.g. generators, induction motors, AVRs etc.) in the short-term time scale are substituted by their equilibrium equations.

- The dynamic phenomena in the long-term time scale (LTCs, overexcitation limiters, thermostatic loads, etc.) are represented by differential, or difference equations.

- The network is represented by algebraic equations.

The QSS simulation consists of successive solution of the equilibrium equations of short-term dynamics together with the network constraints. Power system devices and components contributing to voltage instability problems are modeled in detail. In particular, magnetic saturation of synchronous generators is represented, as well as governor action, generation excitation limits, AVR droop of proportional controllers. AGC, etc.

The QSS technique offers a good compromise between the advantages of time-simulation and the efficiency of static methods, needed to analyze a large number of contingencies.

\section{B WPSTAB description}

WPSTAB is a power system long-term simulation package that has been developed at NTUA [2]. An Equilibrium Point Computation Program (EPCP) is implemented in each time step to solve the set of short-term equilibrium and network equations. This program is a generalization of a conventional power flow program and makes full use of the sparsity formulation of the latter.

WPSTAB uses detailed induction motor equilibrium conditions. Moreover it has the ability to analyze a short-term instability and switch to an approximate simulation of induction motors during stalling. It can also use reduced-order models of generators to approximate the system behavior even after the loss of short-term equilibrium, where the QSS approximation breaks down.

This program has been proven reliable for application in bulk power system studies. Its results compared very favorably with those of a full simulation program (ETMSP) [9]. WPSTAB is presently used by PPC for contingency evaluation and the classification of countermeasures against voltage instability and collapse.

\section{ASTRE description}

The ASTRE package developed at ULg covers several aspects of voltage stability and security analysis. As already mentioned, its heart is a fast time domain simulation based on the QSS method. This simulation is complemented by sensitivity and eigenvector analyses, which provide information on the instability mode and the best remedial actions $[2,7]$. This diagnosis capability can be used in both preventive mode (e.g. for generation rescheduling) and curative mode (e.g. for optimal load shedding).

Voltage security analysis is implemented through three modules. The first one is the QSS simulation engine, used for contingency evaluation and instability diagnosis. The second one is a load flow program aimed at stressing the system in its p.e-contingency situation (taking into account secondary violtage control. if any). These two modules are called by a third one, in charge. of the security limit search (including contingency filtering). This limit search is further described in Section VI, where it is applied to the upgraded Greek system.

ASTRE has been used for some time by Electricité de France, Hydro-Québec (Canada) and Electrabel (Belgium). The QSS method was carefully validated against full time domain simulation by the former two companies (e.g. $[7,8]$ ). It is used in various contexts:

- planning studies, where a large number of long-term stability scenarios have to be considered, and for the design of load shedding schemes

- operational planning studies, for the determination of security limits $[5,7]$

- efforts are also devoted to bringing it in the real-time environment.

Extensions to short-term voltage stability analysis are also under investigation.

\section{VOLTAGE STABILITY ANALYSIS OF 1996 EVENT}

Long-term simulations were carried out to investigate the voltage instability event of $8^{\text {th }}$ July of 1996 from 9.00 am to $11.30 \mathrm{am}$. The simulations were performed by both WPSTAB and ASTRE programs (see section III).

The simulated scenario was based on two actual snapshots (at 9.00 and 10.00) of the EMS state estimator, which were retrieved from the EMS data base. Based on these snapshots the rate of load increase at each MV bus was derived. The switching of capacitor banks from 9.00 to 10.00 was also taken into account, as well as the dispatchers' action from 9.00 to 11.30 . The latter consisted mainly in decreasing the active generation at critical power plants (in the Southern part of the system) in an attempt to increase their reactive limits.

In Fig. 2 the measured time response of a critical bus voltage is compared to the ones simulated by WPSTAB (line 1) and ASTRE (line 2). The two programs. as seen in Fig. 2, give practically identical results. It is clear also that QSS simulation was able to reproduce the dominant features of the phenomenon. . The mismatch between the simulations and the measurement is mostly due to the initial difference between measured voltage and state estimator estimate. In the sequel IVPSTAB simulation results are used to explain the nature and the basic mechanisms driving this event.

In Fig. 3 the voltage of the same critical HV bus is plotted versus the total active load of the Athens region. From this PV curve we can draw the following conclusions:

- The maximum power that can be transferred to the Athens region does not exceed $2020 \mathrm{MW}$.

- During the event load admittances (as seen from the 150 $\mathrm{kV}$ side of distribution transformers) increased beyond the value corresponding to this maximum power limit (critical point). This is a definite indication of voltage instability, as it is well known that after the critical point the LTC dynamics become unstable [7].

- As detected by the simulation all LTCs in the affected area reached their limits before the end of the load ramp. This stopped the voltage decline process that could otherwise escalate to a voltage collapse. 


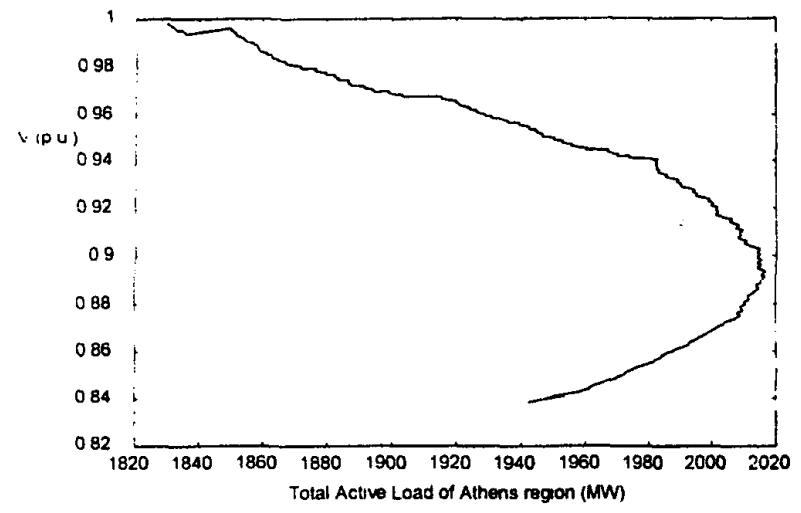

Fig 3 P-V curve of a $150 \mathrm{kV}$ in the Athens region (incident of 1996)

- Before the end of the simulation all generators in the South part (and many more in the other parts) of the system had reached their excitation limits.

Simulation was also used to evaluate the effect of decreasing active generation close to the affected area in order to increase reactive generator output. It was shown that this led to increased reactive power losses at the main corridor between north and south and consequently to further voltage drop. Thus the nature of the problem was determined to be one of corridor flow and not one of local reactive deficit.

\section{COUNTERMEASURES AND SYSTEM UPGRADES}

After the 1996 incident a number of measures both in the short and long term have been taken by PPC to avoid encountering similar phenomena in the future. The defense plan against such phenomena in the short term comprised:

- Increasing of the reference voltages (setpoints) of generators so as to reach $415 \mathrm{kV}$ in the North and $420 \mathrm{kV}$ in the West part of the system.

- Changing of the tap positions in EHV/HV substations in favor of the $400 \mathrm{kV}$ network at the North-central system. This allows power to be transmitted in the North-South direction at a higher voltage reducing reactive losses and increasing reactive production of $400 \mathrm{kV}$ lines.

- Changing of the tap positions in EHV/HV substations in favor of the $150 \mathrm{kV}$ network at the metropolitan area of Athens. This increases the voltage level at the secondary transmission and subtransmission of the $150 \mathrm{kV}$ system.

The actions undertaken for the mid and long term included transmission network reinforcements. installation of new generating units in the Athens region as well as instailation of capacitors in the South part of the system. The measures taken so far are:

- A new $400 \mathrm{kV}$ double-circuit line connecting Athens to the central part of the system was introduced. The construction of this line was completed in 1997, but it was put in operation only in 1999 due to public protest.

- An abandoned power plant in Piraeus feeding the $150 \mathrm{kV}$ network has been converted to burn natural gas and was put back in operation. The nominal capacity of this plant is now $400 \mathrm{MW}$. The plant was out of operation since 1981 for environmental reasons.
- A new combined cycle unit of nominal capacity $560 \mathrm{MW}$. burning natural gas, has been installed at Lavrion, near Athens feeding the $400 \mathrm{kV}$ network.

- Nejw shunt capacitor banks of about $200 \mathrm{MVAr}$ nominal reactive power have been installed in the South part of the system (Athens region and Peloponnese) on the MV side of the HV/MV substations.

Moreover. some further system reinforcements are foreseen for the years 2000-2001. These reinforcements include:

- Upgrade of the connection between Peloponnese and the West of the system by putting two new $150 \mathrm{kV}$ submarine cables of nominal capacity 2 x 175 MVA.

- Upgrade of some lines in the $150 \mathrm{kV}$ network of Northern Peloponnese.

- Restructuring of the $150 \mathrm{kV}$ network in the West part of the system.

\section{VOLTAGE SECURITY ASSESMENT OF THE UPGRADED SYSTEM}

In this section the present state (1999) of the system is evaluated using the forecasted loads of the year 2000 summer peak. Only the existing upgrades discussed above are being considered in the system model. The system consists of 926 buses, 635 transmission lines, 506 transformers and autotransformers, 66 generators and 1 interconnection.

Two separate evaluation studies are performed. First a contingency evaluation of the unavailability of the 4 units missing during the 1996 event, and then the calculation of the secure operation limits for all $\mathrm{N}-1$ contingencies, starting from the base case with all generators available

\section{A. Repetition of 1996 scenario}

For this scenario the 4 units that were out of service during the 1996 incident are removed and a uniform load increase is imposed on the system. This contingency is simulated using WPSTAB and the total Athens region load is plotted versus the voltage of the same bus that was used in Fig. 3 .

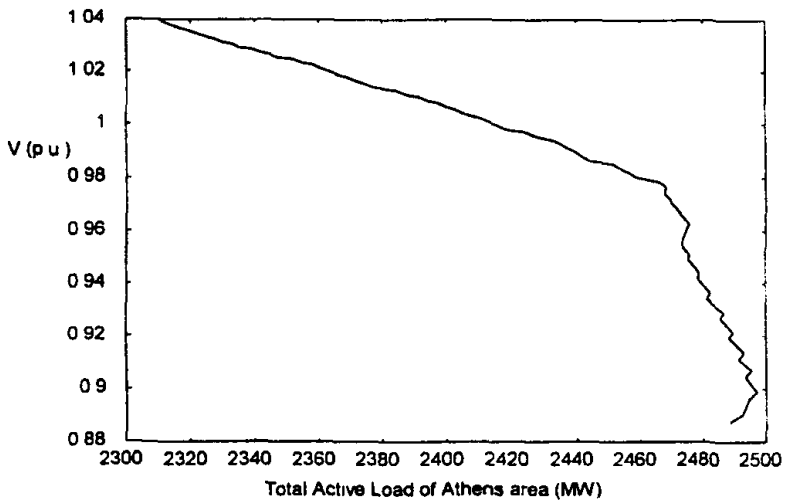

Fig. 4 P.V curve of the same $150 \mathrm{kV}$ bus in the Athens region (upgraded system)

The results are shown in Fig. 4, where it is seen that the maximum power consumption in the Athens area can increase up to $2475 \mathrm{MW}$, whereas in 1996 the maximum consumption was limited to less than $2020 \mathrm{MW}$. 
It is also observed in Fig. 4 that the critical point, where the maximum of power transfer occurs, is crossed at relatively normal voltage leveis. It should be noted that this makes the occurrence of voltage instability much more difficult to detect by simply monitoring voltages.

\section{B Secure operation limits}

Simply stated, Secure Operation Limits (SOLs) indicate how far the system can be stressed prior to any contingency, such that it will remain stable after the contingencies.

The SOL is an easy to interpret voltage security index. It reters to pre-contingency parameters that operators can either observe or control. Also, there is a clear separation between:

(1) the pre-contingency configuration, where operators and/or controllers react to the system stress. and

(ii) the post-contingency configuration, where only automatic controls are considered.

The ASTRE software has been used to evaluate the SOLs of the upgraded Greek system with respect to all N-1 contingencies. The stress imposed is a load increase in the Athens and Peloponnese areas, counter-balanced by a generation in the northern part of the system. starting from the base case. For simplicity, each load is assumed to participate in proportion to its base case power. To avoid false stabilization the LTC limits are removed during SOL computation. The system is stressed using a (pre-contingency) load flow. The maximum stress of interest was set to $700 \mathrm{MW}$ (the corresponding total base case load for the two areas is $2770 \mathrm{MW}$ ).

A set of $789 \mathrm{~N}-1$ contingencies is considered, each corresponding to a single branch tripping. This includes the tripping of generator step-up transformers, which disconnects both the generator and its auxiliaries that are fed from the same bus.

Contingencies are filtered on the basis of the convergence of a post-contingency load flow, run on the system operating at maximum stress ( $700 \mathrm{MW})$. Contingencies, for which the load flow (with constant power loads, thus anticipating the effect of LTCs) converges, are considered harmless and are discarded. The load flow calculations are shortened by:

(i) not taking into account controls that are deemed to improve voltage stability;

(ii) early divergence detecting through the increase of the sum of squared mismatches to avoid unnecessary iterations.

\begin{tabular}{clr}
\multicolumn{3}{c}{ Table ISecure Operation Limits for the upgraded system } \\
\hline No. & \multicolumn{1}{c}{ Contingency description } & $\begin{array}{c}\text { Margin } \\
(\mathrm{MW})\end{array}$ \\
$1-3$ & Loss of a cable feeding Corfu (local effect) & 350 \\
4 & Loss of EHV/HV transtormer & 360 \\
5 & Loss of line in N. Peloponnese (local effect) & 515 \\
6 & Loss of generator MEG4 & 560 \\
7 & Loss of line in N. Peloponnese (local effect) & 570 \\
8 & Loss of line feeding Peloponnese from the & 570 \\
9 & Wost & 670 \\
10 & Loss of generator Nit:G3 new combined cycle plant in Lavrion & \\
\hline
\end{tabular}

0-7803-5935-6/00/\$10.00 (c) 2000 IEEE

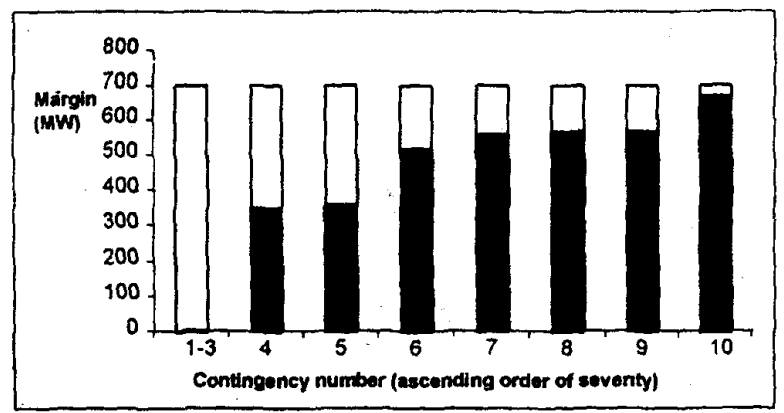

Fig. 5.Secure Operation Limits (SOL) under contingencies

On the other hand. it is essential in this load flow calculation to account for the generator active power rescheduling and reactive power limits. The latter are automatically updated using the overexcitation limiter data available for QSS simulation. After this filtering step, 84 contingencies are declared potentially dangerous. Running a preliminary QSS simulation with ASTRE identifies only 10 contingencies as being really unstable at this maximum stress level. The remaining 72 are false alarms, caused by the conservative character of the load flow calculation. The filtering ratio is expected to be improved in the future.

The secure operation limits of the 10 remaining contingencies are listed in Table $I$ and are also shown graphically in Fig. 5. The light background corresponds to the maximum stress considered.

Contingencies no. 1-3 refer to a local instability mode associated with the loss of one or the other of two $66 \mathrm{kV}$ cisbles feeding the island of Corfu in the Northwest of the system. PPC has already planned the installation :il new 150 $\dot{k V}$ cables as part of the upgrade of the West part of the system. Contingency no. 4 is the first significant contingency corresponding to the loss of a $400 / 150 \mathrm{kV}$ autotransformer in Athens area that is feeding the $150 \mathrm{kV}$ lines to Peloponnese. Contingencies no. 5 and 7 induce a local instability in the northern part of Peloponnese, by creating a large roundabout w'ay of feeding a couple of buses in this area. Contingency no. 6 is the loss of the largest unit in Peloponnese and is the second most significant limiting contingency. Contingency no. 8 amounts to the loss of the generation coming to Peloponnese from the West area. Contingency no. 9 is the loss of the second largest unit of Peloponnese. Contingency no. 10 is the loss of the new combined cycle plant in Lavrion. near Athens.

The SOLs are computed in two steps. In a first step, a "simultaneous binary search" [7] provides the lowest limit (3 contingencies) with the desired accuracy (5 MW in our case) and lower bounds for the less constraining contingencies. At this stage, the user can already figure out the distribution of the various security limits. In a second step, all limits below some threshold (in this case the same $700 \mathrm{MW}$ as in the first step) are refined to meet the specified accuracy.

The security limit computation can be complemented by an instability diagnosis. For a given level of stress and a given contingency, the unstable QSS time evolution of the system is analyzed through sensitivity and eigenvector analysis calculations. The corresponding results have confirmed the 
above interpretation of the limiting contingencies.

The computing (elapsed) times on a $450-\mathrm{MHz} \mathrm{PC}$ (running NT4.0) are as follows:

- 38 seconds for the prefiltering load flow

- 110 seconds for the simultaneous binary search

- 96 seconds for the subsequent limit refinement.

The approach is thus computationally very efficient and allows to envisage real-time application in a near future.

\section{CONCLUSIONS}

Analysis showed that the 1996 incident was indeed due to voltage instability in the Athens region and the southern part of the system (Peloponnese). The subsequent system upgrades (new generation, new $400 \mathrm{kV}$ line and capacitor banks) were proven to be very efficient in reinforcing the Athens region, so as to achieve larger loading margins even for the generation unavailability that led to the 1996 event.

The calculation of SOLs demonstrated that, the security margins are acceptable for all single contingencies (with the exception of those having only local effects). However, the nature of the limiting contingencies signifies that the region of Peloponnese, is rapidly becoming the most stressed part of the system. To this end, the upgrades already planned by PPC for next year, and particularly the reinforcement of the link between Peloponnese and western Greece. seem to be extremely timely. Also. a thorough stability analysis of the Peloponnese area is recommended.

The results of the SOL analysis indicate that the most significant contingencies for voltage stability are the tripping of a $400 / 150 \mathrm{kV}$ autotransformer in the Athens area and the loss of the largest generator in Peloponnese. The inclusion of an on-line VSA function in the national EMS is currently being considered by PPC.

\section{ACKNOWLEDGEMENT}

The authors wish to acknowledge the contributions of $\mathrm{Dr}$. T. Koronides of PPC, who provided the EMS historic data files for the 1996 incident. Ass. Prof. A. Kladas who helped with the comparison of the initial 1996 load flows and Ms. M. Efstathiou. PPC engineer and NTUA graduate student, who helped in preparing the set of data for the upgraded system. Thanks are also due to Dr. A. Maissis, Director of PPC System Studies Dept., for his help and encouragement.

\section{REFERENCES}

[1] C.Vournas (scuentıfic coordinator). "Investigation of low-voltage problems in the transmission network of PPC". project final report, Department of ECE. NTUA. Dec. 1997 (in Greek).
[2] T Van Cutsem, Y. Jacquemart. J - N Marquet. $P$ Pruvot, " $\Lambda$ comprehensive analysis of mid-term voltage stability". IEEE Transactions on Power Systems. Vol. 10. 1995, pp. 1173-1182

[3] C. Voumas (scientific coordinator). "Development of software for voltage stability analysis - Application to the Greek interconnected system". phase A final report, project 95 S $\$$ N96 funded by the General Secretariat for Research and Technology, Athens. April 1999.

it C. D Voumas, G. A. Manos, "Long-term Simulation in the Vicinity of Short-term Instabilities. $13^{\text {th }}$ Power System Computational Conference. Trondheım Norway. Iune 1999. pp. 1146-1154.

[5] T. Van Cutsem. "A comprehensive voltage security assessment". paper presented at the panel session on "Techniques for voltage stability limit search". IEEE 1998 Winter Power Meeting, Tampa (to be published by IEEE)

[6] P. Kokotovic. H. K. Khalil, J. O'Reslly, "Singular Perturbation Methods in Control. Analysis and Design". Academic Press. 1986.

[7] T Van Cutsem, C. Voumas. "Ioltage Stability of Electric Power Sistems", Kluwer Academic Press, 1998.

[8] T Van Cutsem. R. Mailhot. "Validation of a fast voltage stability analysis method on the Hydro-Québec sy stem". IEEE Transactions on Power Systems, Vol. 12, 1997. pp. 282,292

[9] C. D. Vournas, G. A. Manos, P. W Sauer. M. A. Pai, "Effect of Overexcitation limiters on power system long-term modelling", to appear in IEEE Trans, on Energy Conversion.

\section{BIOGRAPHIES}

Costas D. Vournas received the Diploma of Electrical and Mechanical Engineerıng from NTUA in 1970, the MSc in Electrical Engineerıng from the University of Saskatchewan in 1976 and the Doctor of Engineering again from NTUA in 1986. He is currently Professor in the Electrical Energy Systems Lab of the Dept of Electrical and Computer Engineering of NTUA $\mathrm{His}$ research interests include voltage stability analysis, as well as power system control.

George A. Manos received the Diploma of Electrical and Computer Engineering from NTUA in 1993 and the Doctor of Engineering from the same University in 1998 . He has participated in various projects involving voltage stability and frequency analysis of the Greek system and is currently wiorking part time for PPC.

John Kabouris received the Diploma of Electrical Engineering in 1985 ard the Doctor of Engineering degree in 1992 from NTUA. In 1991 he joined PPC. where he is currently with the System Studies Department. His research interests include power system analysis and renewable energy scurces.

Thierry Van Cutsem graduated in Electrical and Mechanical Engineering from the University of Liège (Belgium) in 1979. where he obtained the Ph.D. degree in 1983 and is now iecturer. Since 1980. he has bcen with the FNRS (Belgian National Fund for Scientific Research). of which he is now a Research Director. His interests are in power system dvnamics. control and stability, numerical simulation and security analysis. 